\title{
A Novel Isolate with Deletion in GP3 Gene of Porcine Reproductive and Respiratory Syndrome Virus from Mid-Eastern China
}

\author{
Baochao Fan, Hai Wang, Juan Bai, Lili Zhang, and Ping Jiang \\ Key Laboratory of Animal Diseases Diagnostic and Immunology, Ministry of Agriculture, College of Veterinary Medicine, \\ Nanjing Agricultural University, Nanjing 210095, China \\ Correspondence should be addressed to Ping Jiang; jiangp@njau.edu.cn
}

Received 10 October 2013; Revised 5 December 2013; Accepted 18 December 2013; Published 12 February 2014

Academic Editor: Denis Archambault

Copyright (c) 2014 Baochao Fan et al. This is an open access article distributed under the Creative Commons Attribution License, which permits unrestricted use, distribution, and reproduction in any medium, provided the original work is properly cited.

\begin{abstract}
PRRSV strain SH1211 was isolated from the lung tissue of a piglet on a large-scale pig farm with approximately $30 \%$ morbidity and 50\% mortality in mid-eastern China in 2012. The full-length genome of SH1211 was $15313 \mathrm{nt}$ in size, excluding the polyadenylated sequences, and shared $94.9 \%$ nucleotide sequence identity with the HP-PRRSV strain, JXA1. The GP2 and GP5 proteins of SH1211 shared only $91.5 \%$ and $85.1 \%$ amino acid sequence identities with those of the JXA1, respectively. A deletion at amino acid positions 68 and 69 was identified in the GP3 protein of SH1211, compared with the GP3 of Type-2 PRRSV isolates. A phylogenetic tree based on the nucleotide sequence of the complete genome showed that SH1211 is the most closely related to other HP-PRRSV strains isolated in China. However, phylogenetic analysis based on the GP2 and GP5 proteins showed that SH1211 is the most closely related to the QYYZ strain. A recombination analysis indicated that SH1211 might have been generated through recombination events between the JXA1 and QYYZ in which the GP2 and GP5 coding sequences were exchanged. Thus, SH1211 is a novel PRRSV strain with significant variation. Our analysis of SH1211 provides insight into the role of genetic variation in the antigenicity of PRRSVs in China.
\end{abstract}

\section{Introduction}

Porcine reproductive and respiratory syndrome virus (PRRSV), which causes great economic losses to the swine industry worldwide $[1,2]$, was first isolated in the Netherlands in 1990 [3] and was later identified in the USA [4]. The PRRSVs are divided into Type-1 (European, Lelystad prototype strain) and Type-2 (North American, VR-2332 prototype strain) genotypes, which vary in nucleotide sequence by approximately $60 \%[5,6]$. Along with equine arteritis virus, lactate dehydrogenase-elevating virus, and simian hemorrhagic fever virus, the PRRSVs are members of the order Nidovirales and family Arteriviridae [7, 8].

The PRRSV genome is 15000 to $15500 \mathrm{nt}$ in length and consists of a $5^{\prime}$-untranslated region (UTR), at least 9 open reading frames (ORFs) that encode viral proteins, and a $3^{\prime}$ UTR $[8,9]$. The ORFs la and lb occupy the first two-thirds of the single-stranded, positive-sense RNA genome. These
ORFs encode the ORFlab replicase polyprotein, which is proteolytically cleaved into 13 small nonstructural proteins that are involved in virus replication and transcription $[10,11]$. The PRRSV ORFs 2-7 encode a series of viral structural proteins that are associated with the virus envelope, including the GP2, E, GP3, GP4, GP5, M, and N proteins [8, 12-14]. A recent study identified ORF5a, which overlaps with the GP5coding sequence and encodes a small hydrophobic protein $[15,16]$.

The PRRSV is characterized by extensive genetic variation, and a number of genetically/antigenically diverse strains have been identified [5, 17]. The coding region for the nonstructural protein 2 (nsp2) of PRRSV displays substantial genetic variation, including point mutations, insertions, and deletions [18-21]. The GP5 protein, a major component of the viral envelop, is thought to induce virus-neutralizing antibodies $[22,23]$ and displays the highest level of genetic variability among the PRRSV structural proteins [24, 25]. 
TABLE 1: Primers used for RT-PCR and RACE amplification for SH1211.

\begin{tabular}{|c|c|c|}
\hline $\begin{array}{l}\text { Primers } \\
\text { name }\end{array}$ & Sequence & $\begin{array}{l}\text { Genome } \\
\text { position } \\
\text { in JXA1 }\end{array}$ \\
\hline A1-400 & $5^{\prime}$-AGCACTCGACAGTG-3' & 400 \\
\hline S1-412 & $5^{\prime}$-CGATTGCACGAATGACTA- $3^{\prime}$ & 412 \\
\hline A2-381 & 5'-TGCACGTGGCAACGTC-3’ & 381 \\
\hline S2-437 & $5^{\prime}$-CGATTGCACGAATGACTA- $3^{\prime}$ & 437 \\
\hline RT488 & 5'-CGCACCATTCTTTGTTGA-3' & 488 \\
\hline F-322 & 5'-GGGGTGCTGGGTCTATT-3' & 322 \\
\hline $\mathrm{R}-2352$ & $5^{\prime}$-ATAGCAATTGGACAGTGAGAAG-3' & 2352 \\
\hline F-2244 & $5^{\prime}$-CGAACAACCTCACGTCAACTCA-3' & 2244 \\
\hline $\mathrm{R}-4588$ & $5^{\prime}$-GTAATACCCGCAAGCACTTTAC-3' & 4588 \\
\hline F-4512 & $5^{\prime}$-GAAGAGGATTACGGCTAGAACT-3' & 4512 \\
\hline $\mathrm{R}-6878$ & $5^{\prime}$-TTATCAACCTGTACCAACTGAG-3' & 6878 \\
\hline F-6781 & $5^{\prime}$-TCTGCGTCCAACATGAGGAATG-3' & 6781 \\
\hline R-9137 & $5^{\prime}$-CAGCACAAGGTCGTCCGAATAG-3' & 9137 \\
\hline F-9059 & $5^{\prime}$-GTTTCTGCAAGACCAGCTAAAG-3' & 9059 \\
\hline R-11471 & 5'-CTCCTTGAAGTCCAACATCACT-3' & 11471 \\
\hline F-11387 & $5^{\prime}$-GGATGTGTACCTCCCAGACCTT-3' & 11387 \\
\hline R-13812 & 5'-TATGAGAGCTGTTGTTGTTGCT-3' & 13812 \\
\hline F-13683 & 5'-TTTGAATGTTCAAGTATGTTGG-3' & 13683 \\
\hline R-14755 & $5^{\prime}$-ACCCAACACGAGGCTTTTCAAC-3' & 14755 \\
\hline $3^{\prime} \mathrm{RACE}$ & 5'-ACATTCGTGCACTTTGAGAG-3' & 14465 \\
\hline
\end{tabular}

The GP3 protein is the second most heterogeneous structural protein, and the GP3 proteins of North American and European isolates share $54 \%$ to $60 \%$ amino acid sequence identity [26]. The GP3 protein has been the focus of studies of the genetic diversity, phylogenetic relationships, and molecular epidemiology of PRRSVs.

Although PRRSV isolates from all over the world cause similar symptoms and clinical features in pigs, previous studies have indicated that PRRSVs are antigenically, genetically, and pathologically heterogeneous $[25,27,28]$. In our current study, we isolated a novel PRRSV, the SH1211 strain, from a piglet on a large-scale pig farm with high morbidity and mortality in mideastern China in 2012. The genome of SH1211 was sequenced and analyzed to investigate the relationship between genetic variation and antigenicity among PRRSV isolates in China.

\section{Materials and Methods}

2.1. Clinical Samples. The lung tissue sample was obtained from a PRRSV-vaccinated piglet on a large-scale pig farm with approximately 30\% morbidity and 50\% mortality in Shanghai, China, in 2012. The piglet displayed clinical signs and symptoms that were typical of the porcine reproductive and respiratory syndrome (PRRS), including labored breathing, pyrexia, lethargy, and anorexia. The animal was diagnosed as PRRSV-positive using reverse transcription (RT) and polymerase chain reaction (PCR).
2.2. Virus Isolation. The lung tissue was homogenized and used to inoculate primary porcine alveolar macrophage (PAM) cells. The PAM cells were maintained in RPMI 1640 growth medium containing $10 \%$ heat-inactivated fetal bovine serum, $100 \mu \mathrm{g} / \mathrm{mL}$ penicillin, and $100 \mathrm{U} / \mathrm{mL}$ streptomycin at $37^{\circ} \mathrm{C}$ in a $5 \% \mathrm{CO}_{2}$ atmosphere until a cytopathic effect became visible. The infected cells were lysed using a freezethaw method and centrifuged at $2000 \times \mathrm{g}$ for $10 \mathrm{~min}$. The supernatant was stored at $-70^{\circ} \mathrm{C}$.

2.3. RNA Extraction and RT. Total RNA was extracted from the tissue homogenate using the RNeasy Mini Kit (Qiagen, Hilden, Germany) and suspended in nuclease-free water immediately before use. The RT procedure was performed using the SuperScript III First-Strand Synthesis Kit (Invitrogen, Carlsbad, CA, USA). Samples containing $8 \mu \mathrm{L}$ of total RNA, $1 \mu \mathrm{L}$ of $50 \mu \mathrm{M}$ oligo $(\mathrm{dT})_{20}$ primer, and $1 \mu \mathrm{L}$ of $10 \mathrm{mM}$ dNTP mix were incubated at $65^{\circ} \mathrm{C}$ for $5 \mathrm{~min}$ for primer annealment and placed on ice for at least $1 \mathrm{~min}$ immediately afterward. For first-strand synthesis, $2 \mu \mathrm{L}$ of $10 \times$ RT buffer, $4 \mu \mathrm{L}$ of $25 \mathrm{mM} \mathrm{MgCl}_{2}, 2 \mu \mathrm{L}$ of $0.1 \mathrm{M} \mathrm{DTT}, 1 \mu \mathrm{L}$ of $40 \mathrm{U} / \mu \mathrm{L}$ RNaseOUT (Invitrogen), and $1 \mu \mathrm{L}$ of $200 \mathrm{U} / \mu \mathrm{L}$ Superscript III reverse transcriptase were added to each sample, and the samples were incubated at $50^{\circ} \mathrm{C}$ for $50 \mathrm{~min}$. The $\mathrm{RT}$ reaction was terminated by incubation at $85^{\circ} \mathrm{C}$ for $5 \mathrm{~min}$, and the samples were placed on ice until complementary DNA (cDNA) synthesis was performed.

2.4. Primer Design and cDNA Synthesis. The ORF5 nucleotide sequence of SH1211 was compared with that of other PRRSV isolates available in GenBank database (NCBI) to identify similarities, upon which primers were designed. The SH1211 genome was divided into 7 overlapping fragments for amplification, and the $5^{\prime}$ and $3^{\prime}$ termini of the genomic sequence were synthesized using rapid amplification of the cDNA ends (RACE). The sequences of the primers used for the whole genome and the RACE procedure are provided in Table 1. The overlapping fragments were amplified by PCR using the Phanta Super Fidelity DNA Polymerase (Vazyme, China), and the thermal cycling was performed at $95^{\circ} \mathrm{C}$ for $3 \mathrm{~min}$, followed by 35 cycles of $95^{\circ} \mathrm{C}$ for $10 \mathrm{~s}, 52^{\circ} \mathrm{C}$ to $56^{\circ} \mathrm{C}$ for $30 \mathrm{~s}$, and $72^{\circ} \mathrm{C}$ for $2 \mathrm{~min}$, with a final extension at $72^{\circ} \mathrm{C}$ for $10 \mathrm{~min}$. The amplified PCR products were analyzed using agarose gel electrophoresis.

2.5. Genome Cloning and Sequencing. The PCR products were purified from the agarose gel using the AxyPrep DNA Gel Extraction Kit (Axygen, China) and cloned into the pEASY-Blunt Zero vector (Trans, China). Three clones were sequenced by a commercial service provider (Invitrogen, Shanghai, China).

2.6. Nucleotide and Amino Acid Sequence Analyses. The overlapping sequences of the PCR products were combined to obtain the full-length genomic sequence of the SH1211 strain. A nucleotide BLASTn analysis was used to compare the sequences of the SH1211 genes with those of the reference strains of PRRSV in the GenBank database (Table 2). 
TABLE 2: Representative PRRSV Strains used in this study.

\begin{tabular}{|c|c|c|c|c|}
\hline No. & Name & Country & Year & $\begin{array}{c}\text { Accession } \\
\text { number }\end{array}$ \\
\hline 1 & $\mathrm{CH}-1 \mathrm{a}$ & China & 1996 & AY032626 \\
\hline 2 & BJ -4 & China & 2000 & AF331831 \\
\hline 3 & $\mathrm{HB}-1(\mathrm{sh}) / 2002$ & China & 2002 & AY150312 \\
\hline 4 & HEB1 & China & 2006 & EF112447 \\
\hline 5 & JXA1 & China & 2006 & EF112445 \\
\hline 6 & HUB2 & China & 2006 & EF112446 \\
\hline 7 & $\mathrm{HuN}$ & China & 2007 & EF517962 \\
\hline 8 & SY0608 & China & 2007 & EU144079 \\
\hline 9 & 07NM & China & 2007 & FJ393456 \\
\hline 10 & BJ & China & 2007 & EU825723 \\
\hline 11 & $\mathrm{CH}-1 \mathrm{R}$ & China & 2008 & EU807840 \\
\hline 12 & YN9 & China & 2008 & GU232738 \\
\hline 13 & $08 \mathrm{HuN}$ & China & 2008 & GU169411 \\
\hline 14 & 09HUB2 & China & 2009 & JF268683 \\
\hline 15 & 10GX-1 & China & 2010 & JQ663558 \\
\hline 16 & 10HEB-1 & China & 2010 & JQ663551 \\
\hline 17 & WUH4 & China & 2011 & JQ326271 \\
\hline 18 & QYYZ & China & 2011 & JQ308798 \\
\hline 19 & YD & China & 2012 & JF748717 \\
\hline 20 & SD16 & China & 2012 & JX087437 \\
\hline 21 & SH1211 & China & 2012 & KF678434 \\
\hline 22 & LMY & South Korea & 2002 & DQ473474 \\
\hline 23 & VR-2332 & USA & 1992 & AY150564 \\
\hline 24 & EuroPRRSV & USA & 1999 & AY366525 \\
\hline 25 & MN184C & USA & 2007 & EF488739 \\
\hline 26 & Ingelvac ATP & USA & & DQ988080 \\
\hline 27 & Prime Pac & USA & & DQ779791 \\
\hline 28 & RespPRRS MLV & USA & 1994 & AF066183 \\
\hline 29 & ATCC VR-2332 & USA & 1990 & U87392 \\
\hline 30 & Lelystad virus & Europe & 1991 & M96262 \\
\hline
\end{tabular}

The sequence alignments were generated using the Clustal $\mathrm{W}$ program. Phylogenetic trees of the full-length genomic, GP2, and GP5 nucleotide sequences were generated using the distance-based Neighbor-Joining method in the MEGA, version 5.05, software. The bootstrap values were calculated based on 1000 replicates, and the evolutionary distances were computed using the Jukes-Cantor method. The amino acid (AA) sequence comparisons were obtained using the BioEdit software.

2.7. Recombination Analysis. Multiple sequence alignments between SH1211 and the other PRRSV strains were performed using the Clustal $\mathrm{X}$, version 1.83, program. The Recombination Detection Program (RDP4), version 4.1.3, was used to estimate the potential recombination events [29]. The GENECONV method was used to search for putative breakpoints [30].

\section{Results}

3.1. Comparison of Full-Length Genomic Sequences of SH1211 and Other PRRSV Strains. The sequence analysis showed that the full-length genomic sequence of SH1211 was 15 313 nucleotides in length, excluding the polyadenylated sequences, and included the following genes and UTRs: $5^{\prime}$ UTR (188 nt), Rep (11792 nt), GP2 (771 nt), GP3 (759 nt), GP4 (537 nt), GP5 (603 nt), M (525 nt), N (372 nt), and $3^{\prime}$ UTR (150 nt). The nucleotide sequence of the full-length SH1211 genome was compared with those of the other PRRSV isolates, including two North American strains (MN184C and VR-2332), one European strain (LV), and six Chinese strains (CH-1a, SY0608, QYYZ, JXA1, WUH4, and HB-1(sh)/2002) (Table 3).

The SH1211 strain shared a higher level of nucleotide sequence identity with the Type-2 PRRSV strains $(81.8 \%$ to 95.1\%), compared to that shared with the Type-1 PRRSV strain, LV (58.0\%). The highest levels of shared nucleotide sequence identity (94.9\% to $95.1 \%$ ) were observed between the SH1211 strain and the WUH4, JXA1, and SY0608 strains, which had previously caused epidemics in China. Moreover, the 950-AA sequence of the protein produced from the Nsp2 gene (2850 nt) of the SH1211 strain contained 30 noncontiguous AA deletions, relative to that of the Nsp2 gene of the VR2332 strain (Figure 1). These results indicated that the SH1211 strain is highly similar to a group of highly pathogenic (HP) strains of PRRSV previously isolated in China.

The nucleotide lengths of ORF1a and ORF1b of SH1211 were $7422 \mathrm{nt}$ and 4383 nt, respectively. The ORFla and ORF1b of SH1211 shared nucleotide sequence identities of $96.0 \%$ and $94.9 \%$ with those of the JXA1 strain, respectively, whereas it shared $53.2 \%$ and $63.0 \%$ with those of the LV strain, respectively. The predicted AA sequences of the proteins of SH1211 shared $97.2 \%$ to $99.4 \%$ identity with those of the JXA1 strain, except for the Nsp1 $\beta$, Nsp2, and Nsp12 proteins, which were only $92.6 \%, 94.2 \%$, and $93.4 \%$, respectively. The Nsp1 $\beta$ protein of SH1211 shared $91.6 \%$ AA sequence identity with that of the SY0608 strain. These data indicated that a high level of variation occurred in the Nsp1 $\beta$ protein of the SH1211 strain.

The comparisons of the sequences of ORFs 2 through 7 showed that the SH1211 strain shared $84.4 \%$ to $97.5 \%$ nucleotide sequence identity with the Type-2 PRRSV strains. The ORF2 and ORF5 of SH1211 exhibited the highest levels of variability, compared with the various HP-PRRSV strains, with $91.3 \%$ and $84.4 \%$ nucleotide sequence identities shared with the JXA1 strain, respectively. The levels of nucleotide sequence identity shared between the SH1211 and JXA1 strains for the other ORFs ranged from $94.9 \%$ to $97.5 \%$. The ORF2 and ORF5 of SH1211 shared nucleotide sequence identities of $92.9 \%$ and $92.8 \%$, respectively, with the QYYZ strain, and the predicted proteins for ORFs 2 and 5 of SH1211 shared AA sequence identities of $93.3 \%$ and $94.0 \%$, respectively, with those of the QYYZ strain.

3.2. Phylogenetic Analyses. Phylogenetic trees were produced based on the nucleotide sequences of the full-length genome, ORF2, and ORF5 of SH1211 and the various PRRSVs 
TABLE 3: Nucleotide and deduced amino acid identities of SH1211 compared with those of WUH4, QYYZ, HB-1(sh)/2002, JXA1, SY0608, MN184C, VR-2332, CH-1a, and LV (\%).

\begin{tabular}{|c|c|c|c|c|c|c|c|c|c|}
\hline \multirow{2}{*}{ SH1211\% } & \multicolumn{9}{|c|}{ Identity to SH1211 } \\
\hline & WUH4 & QYYZ & HB-1(sh)/2002 & JXA1 & SY0608 & MN184C & VR-2332 & $\mathrm{CH}-1 \mathrm{a}$ & LV \\
\hline \multicolumn{10}{|l|}{ Nucleotides (length) } \\
\hline $5^{\prime}$ UTR (188) & 96.8 & 92.6 & 93.6 & 96.8 & 96.3 & 88.9 & 91.0 & 94.2 & 53.3 \\
\hline ORFla (7422) & 96.1 & 82.0 & 93.0 & 96.0 & 96.1 & 76.5 & 84.7 & 90.8 & 53.2 \\
\hline ORF1b (4383) & 94.8 & 89.0 & 93.9 & 94.9 & 94.9 & 86.4 & 89.9 & 92.8 & 63.0 \\
\hline ORF2 (771) & 91.3 & 92.9 & 92.2 & 91.3 & 91.4 & 87.1 & 91.1 & 92.7 & 63.8 \\
\hline ORF3 (759) & 94.9 & 88.7 & 92.9 & 95.2 & 95.6 & 84.7 & 87.3 & 92.9 & 61.5 \\
\hline ORF4 (537) & 96.0 & 93.8 & 94.4 & 95.3 & 96.8 & 86.2 & 89.1 & 94.4 & 64.3 \\
\hline ORF5 (603) & 83.9 & 92.8 & 84.4 & 84.4 & 84.4 & 85.0 & 84.5 & 85.5 & 59.0 \\
\hline ORF6 (525) & 97.5 & 90.0 & 97.1 & 97.5 & 97.5 & 90.6 & 94.6 & 95.2 & 68.5 \\
\hline ORF7 (372) & 96.7 & 87.9 & 96.2 & 97.0 & 96.7 & 90.0 & 92.2 & 94.8 & 61.5 \\
\hline $3^{\prime} \mathrm{UTR}(150)$ & 98.0 & 84.9 & 94.7 & 98.0 & 97.3 & 90.7 & 54.9 & 94.7 & 55.9 \\
\hline Complete $(15,313)$ & 95.0 & 86.0 & 92.9 & 94.9 & 95.1 & 81.8 & 87.4 & 91.7 & 58.0 \\
\hline \multicolumn{10}{|l|}{ Amino acid (length) } \\
\hline nspla (180) & 94.4 & 96.1 & 97.7 & 99.4 & 99.4 & 94.4 & 95.0 & 96.6 & 65.0 \\
\hline nsplb (203) & 92.6 & 81.2 & 90.6 & 92.6 & 91.6 & 75.8 & 80.2 & 84.2 & 39.7 \\
\hline nsp2 (950) & 94.1 & 74.6 & 89.2 & 94.2 & 94.1 & 62.3 & 76.7 & 84.8 & 33.8 \\
\hline nsp3 (446) & 97.6 & 90.0 & 96.9 & 98.0 & 98.0 & 93.0 & 95.3 & 98.0 & 56.1 \\
\hline nsp4 (204) & 98.0 & 91.1 & 97.5 & 98.0 & 98.0 & 93.1 & 94.1 & 95.5 & 62.7 \\
\hline nsp5 (170) & 98.2 & 84.9 & 98.2 & 98.2 & 97.6 & 85.8 & 92.3 & 94.7 & 71.1 \\
\hline nsp6 (16) & 100 & 100 & 100 & 100 & 100 & 93.7 & 93.7 & 100 & 75.0 \\
\hline nsp7 (259) & 98.0 & 94.5 & 95.7 & 98.4 & 98.4 & 84.9 & 88.4 & 95.3 & 43.7 \\
\hline nsp8 (45) & 97.7 & 97.7 & 95.5 & 97.7 & 97.7 & 95.5 & 97.7 & 97.7 & 66.6 \\
\hline nsp9 (643) & 98.3 & 98.3 & 96.7 & 97.3 & 97.7 & 96.0 & 97.8 & 98.1 & 75.9 \\
\hline nsp10 (441) & 97.2 & 96.3 & 97.1 & 97.2 & 97.1 & 93.9 & 94.8 & 96.8 & 65.0 \\
\hline nspl1 (223) & 98.6 & 95.5 & 96.8 & 98.2 & 98.2 & 94.6 & 96.4 & 97.7 & 76.3 \\
\hline nsp12 (153) & 93.4 & 92.1 & 93.4 & 93.4 & 94.3 & 94.7 & 91.5 & 93.4 & 39.2 \\
\hline GP2 (257) & 91.0 & 93.3 & 90.6 & 91.0 & 91.0 & 84.3 & 88.6 & 91.7 & 60.1 \\
\hline $\mathrm{E}(74)$ & 90.5 & 95.9 & 90.5 & 90.5 & 90.5 & 93.2 & 93.2 & 90.5 & 70.2 \\
\hline GP3 (253) & 92.5 & 85.4 & 89.3 & 93.3 & 94.0 & 85.0 & 85.8 & 89.3 & 53.0 \\
\hline GP4 (179) & 95.5 & 94.3 & 97.1 & 94.3 & 97.7 & 89.3 & 89.3 & 97.1 & 69.3 \\
\hline GP5 (201) & 84.5 & 94.0 & 84.5 & 85.0 & 84.5 & 85.0 & 82.5 & 85.5 & 52.6 \\
\hline M (175) & 98.8 & 96.5 & 98.8 & 98.8 & 98.8 & 96.5 & 97.7 & 97.1 & 79.3 \\
\hline $\mathrm{N}(124)$ & 97.5 & 91.0 & 95.9 & 97.5 & 96.7 & 91.0 & 93.4 & 94.3 & 58.0 \\
\hline
\end{tabular}

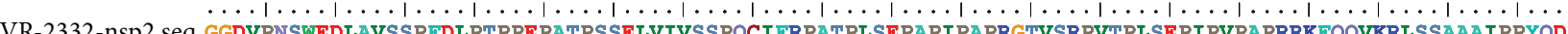

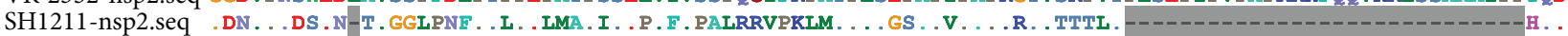

JXA1-nsp2.seq .DN...GS.E-T.GG.LNE...S..M..M..P.L.PASRRVPKLM....GS..V....R..TTTL.

SY0608-nsp2.seq .DN...GS.E-T.GG.LNF...S..M. .M..P.I.PASRRVPKIM. ..GGS..V....R. .TTTL.

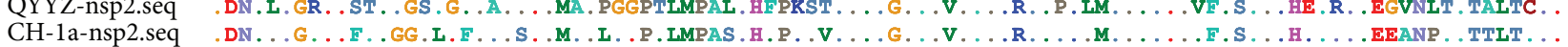

FIGURE 1: Alignment of partial nsp2 amino acid sequence of SH1211 with several representative PRRSV strains. The amino acid deletions are shown with grey bar.

(Figures 2(a)-2(c), resp.). The sum of the branch lengths for the optimal trees for the full-length genome, ORF2, and ORF5 sequences were 1.057, 0.843, and 1.070, respectively. Based on the full-length genome sequence, the PRRSV strains were divided into subgroups 1-4. The SH1211 strain was assigned to subgroup 4, which consisted of 17 PRRSV strains collected in China from 2002 to 2012. However, the SH1211 strain formed a minor branch that was separate from that containing the other subgroup- 4 strains. The ORF2 phylogenetic tree revealed five different subgroups. The SH1211 and QYYZ strains formed subgroup 2, which separated from subgroup 5 by a significant evolutionary distance. The ORF5 phylogenetic tree revealed similar relationships among the various PRRSV strains, with SH1211 and QYYZ forming subgroup 


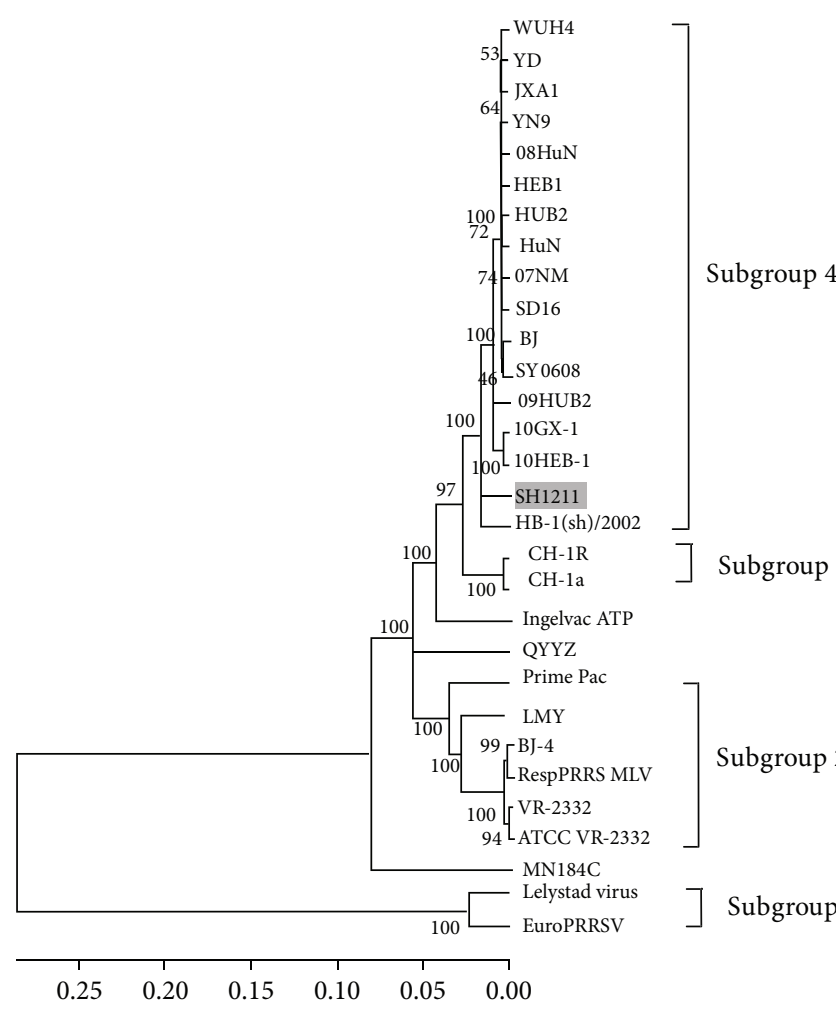

(a)

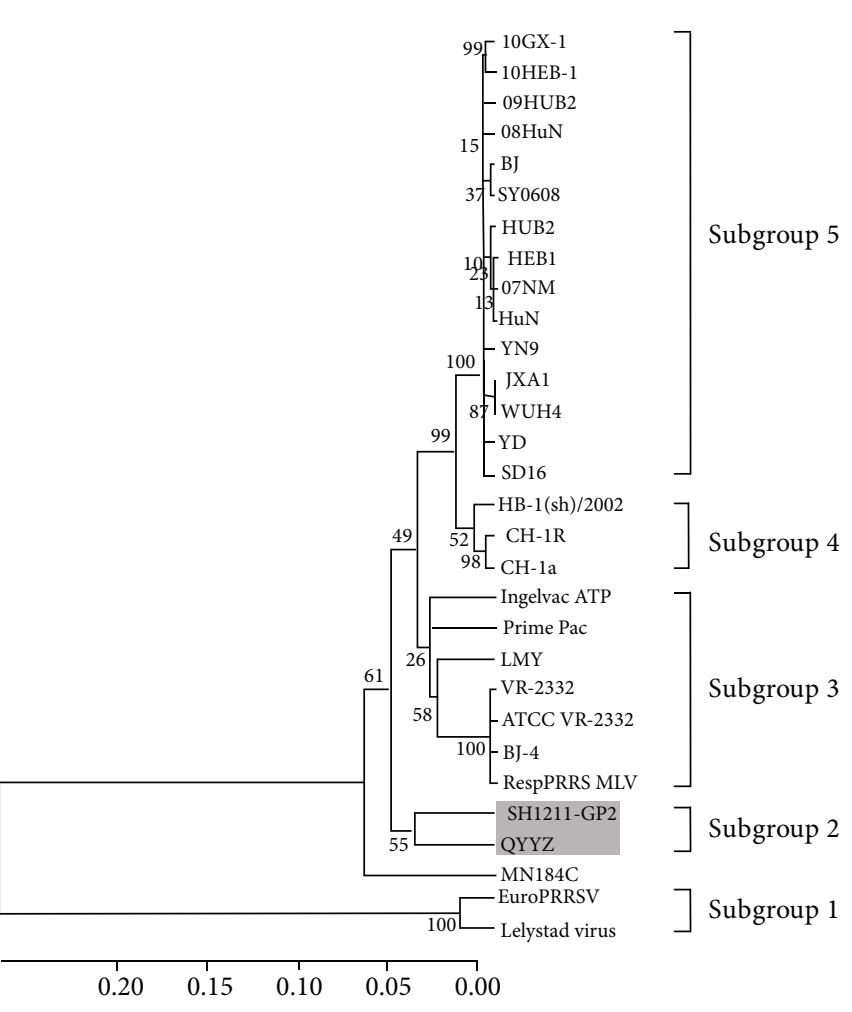

(b)

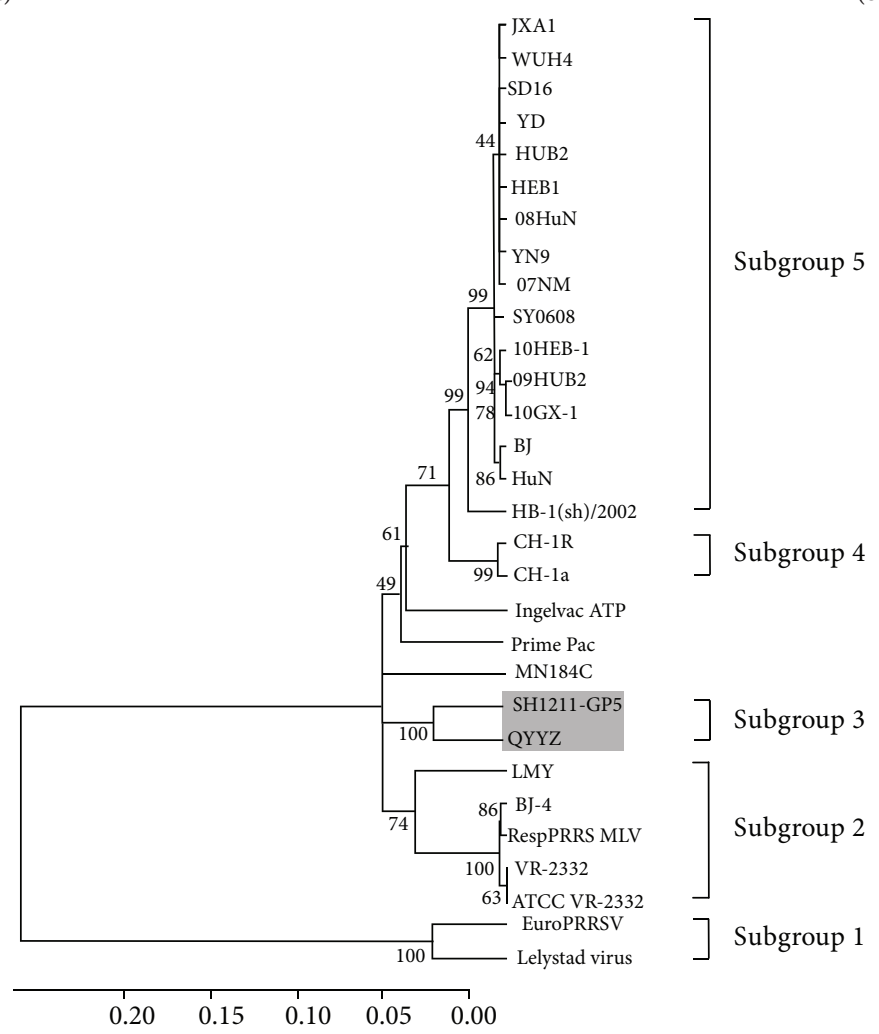

(c)

FIGURE 2: Phylogenetic analysis based on nucleotide sequences of the full-length genome (a), ORF2 (b), and ORF5 (c) of 30 fully sequenced PRRSV isolates. The evolutionary history was inferred using the Neighbor-Joining method. The percentage of replicate trees in which the associated taxa clustered together in the bootstrap test (1000 replicates) was shown next to the branches. The evolutionary distances were computed using the Jukes-Cantor method and were in the units of the number of base substitutions per site. Evolutionary analyses were conducted in MEGA5. 
3. These data indicated that significant variation occurred in ORFs 2 and 5 of SH1211 and QYYZ, compared with the other PRRSVs.

3.3. Recombination Analysis. As shown in Figures 2(b) and 2(c), based on the ORF2 and ORF5 nucleotide sequences, the QYYZ strain displayed the closest phylogenetic relationship with the SH1211 strain. The SH1211 genome was subjected to a recombination analysis, and the potential breakpoints with optimal $P$ values based on the $\chi^{2}$ analysis were identified using the GENECONV method. Four potential recombination breakpoints were identified at nucleotide positions 11697 , 12 768, 13 819, and 14472 (Figure 3), and the approximate $P$ values for the fragments corresponding to nucleotide positions $11697-12768$ and $13819-14472$ were $8.681 \times 10^{-24}$ and $3.178 \times 10^{-35}$, respectively. The GP2 and GP5 genes of the SH1211 strain were located within these two recombinant regions. These data suggest that the JXA1 and QYYZ strains recombined to form the SH1211 strain.

3.4. Sequence Analyses of the UTRs. The 188-nt $5^{\prime}$ UTR of SH1211 shared a higher level of sequence identity $(96.8 \%)$ with JXA1 than that shared with LV (53.3\%). The nucleotide alignments revealed a deletion in the $5^{\prime}$ UTR of SH1211 at nucleotide position 119, relative to the JXA1 and WUH4 strains, and positions 119 and 120, relative to the $\mathrm{CH}$-1a strain. Point mutations were identified in the $5^{\prime}$ UTR of SH1211 at positions $29(\mathrm{C} \rightarrow \mathrm{G}), 57(\mathrm{C} \rightarrow \mathrm{U}), 62(\mathrm{G} \rightarrow \mathrm{C}), 83(\mathrm{~A} \rightarrow$ $\mathrm{G})$, and $156(\mathrm{U} \rightarrow \mathrm{C})$, relative to the $5^{\prime} \mathrm{UTR}$ of the JXA1 strain. Furthermore, the transcription regulatory sequence, UUAACC, was identified at the $3^{\prime}$ boundary of the $5^{\prime}$ UTR in the SH1211 genome. The $3^{\prime}$ UTR of the SH1211 genome shared $84.9 \%$ to $98.0 \%$ sequence identities with the Type- 2 isolates. The $3^{\prime}$ UTR of the SH1211 genome had a deletion at nucleotide position 19, relative to that of the $\mathrm{CH}-1$ a strain (Figure 4(b)), and two point mutations at positions $32(\mathrm{~A} \rightarrow \mathrm{U})$ and $40(\mathrm{G} \rightarrow$ A), relative to the $3^{\prime}$-UTRs of the JXA1 and WUH4 strains.

3.5. Amino Acid Analysis of GP3. As shown in Figure 5, the GP3 gene of SH1211 had a 6-nt deletion at positions 203208 (corresponding to AA positions 67 and 68), relative to the GP3 gene of the Type-2 PRRSV strains. A two-AA deletion $\left(\mathrm{E}^{68}\right.$ and $\left.\mathrm{P}^{69}\right)$ was identified in the antigenic region of the predicted GP3 polypeptide, relative to that of the other PRRSVs examined. The AA substitutions, $\mathrm{T}^{64} \rightarrow \mathrm{A}^{64}, \mathrm{Y}^{67} \rightarrow \mathrm{L}^{67}$, $\mathrm{R}^{71} \rightarrow \mathrm{K}^{69}, \mathrm{~S}^{72} \rightarrow \mathrm{P}^{70}, \mathrm{~L}^{73} \rightarrow \mathrm{F}^{71}, \mathrm{Y}^{79} \rightarrow \mathrm{H}^{77}, \mathrm{E}^{83} \rightarrow \mathrm{G}^{81}, \mathrm{D}^{85} \rightarrow \mathrm{N}^{83}$, and $\mathrm{I}^{94} \rightarrow \mathrm{V}^{92}$, were identified in the main antigenic region of the predicted GP3 polypeptide of SH1211, relative to the GP3 AA sequence of the RespPRRS MLV strain. In addition, the predicted GP3 polypeptide of SH1211 shared seven potential $\mathrm{N}$-glycosylation sites, $\mathrm{N}^{29}, \mathrm{~N}^{42}, \mathrm{~N}^{50}, \mathrm{~N}^{129}, \mathrm{~N}^{150}, \mathrm{~N}^{158}$, and $\mathrm{N}^{193}$, with the Type-2 PRRSV strains [31].

3.6. Amino Acid Analysis of GP5. Most of the AA substitutions identified in the predicted GP5 polypeptide of SH1211 were located within residues 1 to 31 in the $\mathrm{N}$-terminal signal sequence, residues 32 to 60 in the hypervariable region of

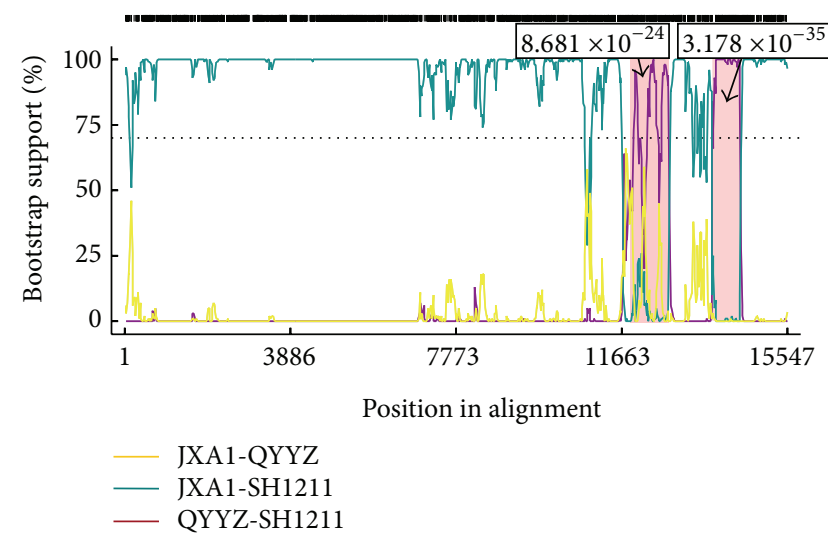

FIgURE 3: The recombinant event of SH1211 was analyzed by the BootScan method in software RDP4. The $x$-axis shows the position in alignment, and the $y$-axis shows the bootstrap support (\%). Major parent plot (blue line) and minor parent plot (purple line) cross two areas (pink regions), which represent the recombinant regions, and the numbers of approximate $P$ values locate at the top of pink regions, respectively. The bootstrap cut-off is $70 \%$.

the ectodomain, and residues 189 to 200 in the C-terminal endodomain (Figure 6). Two AA substitutions, $\mathrm{H}^{38} \rightarrow \mathrm{Y}^{38}$ and $\mathrm{F} / \mathrm{L}^{39} \rightarrow \mathrm{S}^{39}$, were identified in the primary neutralizing epitope (PNE), $\mathrm{S}^{37} \mathrm{H}(\mathrm{F} / \mathrm{L}) \mathrm{QLIYNL}$ [32], of the SH1211 strain, compared with that in the VR-2332 strain and its attenuated vaccine derivative, RespPRRS MLV. No AA mutations were found in the decoy epitope of the predicted GP5 protein of SH1211. Residues 13 and 151 in the GP5 proteins of PRRSVs have been shown to be associated with the virulence [6]. However, the AA substitutions, $\mathrm{H}^{13}$ and $\mathrm{K}^{151}$, were identified in the predicted GP5 protein of the SH1211 strain. To gain further insight into the genetic evolution of SH1211, we also analyzed variation in potential $\mathrm{N}$-glycosylation sites. The predicted GP5 protein of the SH1211 strain shared three Nglycosylation sites with the $\mathrm{CH}-1$ a strain at AA positions 34, 44 , and 51, and the deletion of two N-glycosylation sites at positions 31 and 35 was identified, relative to those in the GP5 protein of the JXA1 strain.

\section{Discussion}

The PRRS continues to be a serious threat, causing a significant economic impact on the swine industry worldwide. Although commercial vaccines against PRRSV are available, traditional control strategies and conventional vaccines have failed to provide sustainable disease control. Surveillance of the recently emerged strains has become necessary because of the considerable genetic and antigenic diversity identified in these HP-PRRSV isolates. In our current study, a novel variant PRRSV strain was isolated from a piglet in a PRRSVvaccinated pig herd with high morbidity and mortality in mid-eastern China.

The GP3 protein of PRRSVs is a minor structural protein. The 254-AA GP3 protein is encoded by ORF3 and has a molecular mass of approximately $42 \mathrm{kDa}[33,34]$. The GP3 protein is one of the most variable structural proteins among 


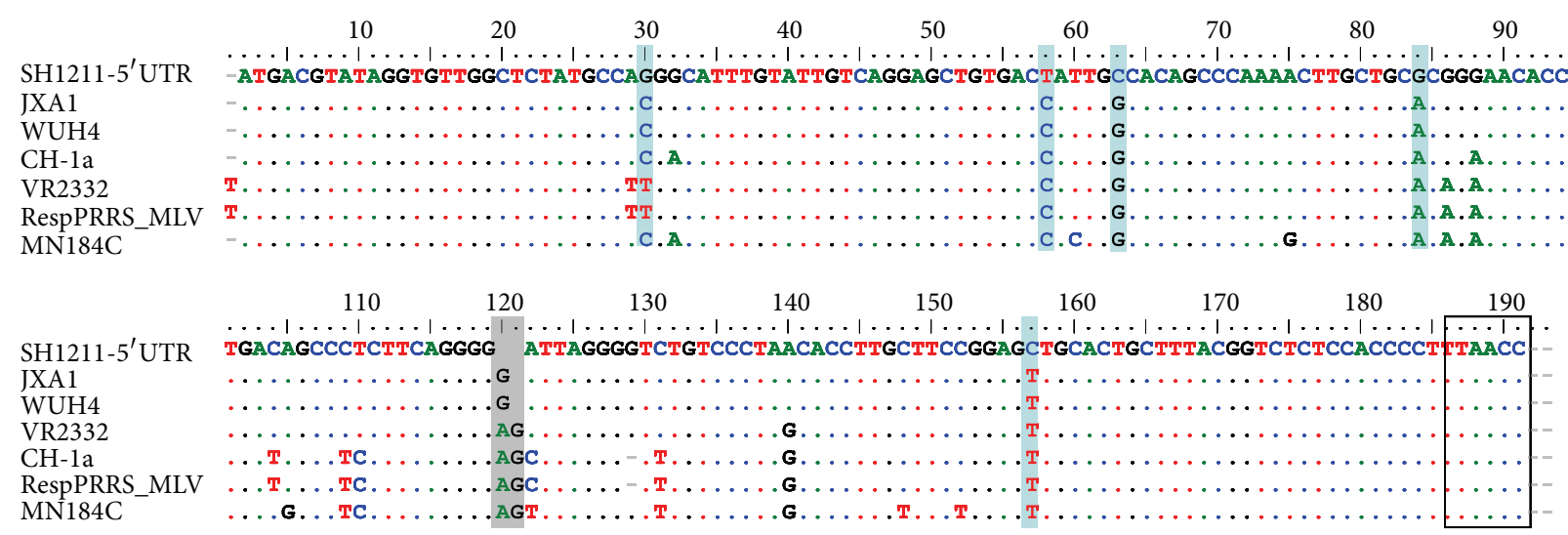

(a)

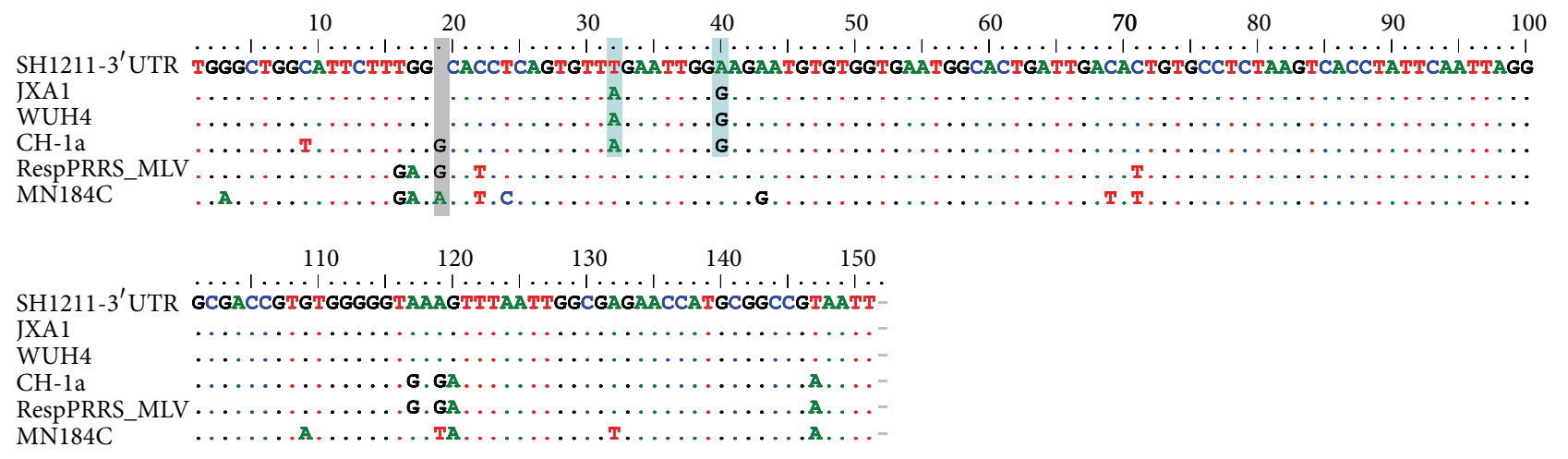

(b)

FIgURE 4: Alignment of nucleotide sequences of $5^{\prime}$ UTR (a) and $3^{\prime}$ UTR (b) of SH1211 with several representative PRRSV strains. The nucleotide deletions and the key nucleotide mutations within the different strains are shown with gray bar and blue bar, respectively. The transcription regulatory sequence (TRS) UUAACC is indicated by a black box.

the PRRSVs, with only $54 \%$ to $60 \%$ AA sequence identity shared between the Type-1 and Type-2 strains $[24,35]$. In the SH1211 strain, the length of ORF3 was 759 nt, and it had a sixnucleotide deletion at positions 203-208, which correspond to AA positions 67 and 68 , relative to the Type-2 PRRSV strains. In the GP3 protein, four consecutive overlapping epitopes, corresponding to AA positions 61-105, were shown to be strongly immunoreactive to $85 \%$ to $100 \%$ of the antiPRRSV sera tested [36]. These epitopes are located in the most hydrophilic region within the GP3 protein, and are considered to comprise an important immunoreactive region of the North American strains of PRRSV [36].

The AA sequence, $\mathrm{Q}^{61} \mathrm{AARQRLEPGRN}{ }^{72}$, of the antigenic region has been shown to be the target of virusneutralizing antibodies [37]. It is notable that a two-AA deletion $\left(\mathrm{E}^{68}\right.$ and $\mathrm{P}^{69}$ ) occurs in the antigenic region of SH1211. Multiple AA substitutions were also identified in the primary antigen region of the GP3 protein of the SH1211 strain, relative to that of the RespPRRS MLV attenuated vaccine strain. A recent study demonstrated that an $\mathrm{N}$-glycan moiety in GP3 is responsible for glycan shield interference, which can influence the ability of the host to produce neutralizing antibodies [38]. However, the two-AA deletion in the GP3 of the SH1211 strain did not affect any of the seven potential N-glycosylation sites identified. Future studies of the sequence diversity in the SH1211 strain are warranted to determine its relationship with immunogenicity.

The envelope protein, GP5, is the most variable protein of the PRRSVs, with only $51 \%$ to $55 \%$ sequence identity shared between the Type-1 and Type-2 strains [28, 35]. Hypervariability in GP5 is likely responsible for the low level of immunological cross-reactivity observed between the PRRSVs [17]. Thus, GP5 has become the focus of analyses of the genetic diversity of PRRSVs [27, 39, 40]. Our analysis of the GP5 of the SH1211 strain revealed significant variation, with only $84.4 \%$ nucleotide identity shared between the ORF5 of SH1211 and that of the representative Chinese HP-PRRSV strain, JXA1. The PNE is also an important domain of GP5 with regard to virus neutralization, and the $\mathrm{H}^{38}(\mathrm{~L} / \mathrm{F})^{39}$ residues in this domain are considered to be critical to the immunogenicity of this epitope [32, 41]. The PNE of the SH1211 strain had the $\mathrm{H}^{38} \rightarrow \mathrm{Y}^{38}$ and $\mathrm{F} / \mathrm{L}^{39} \rightarrow \mathrm{S}^{39}$ AA substitutions in the PNE, which probably contributed to the ability of the isolate to escape neutralizing antibodies induced by PRRSV vaccines used in China, including the attenuated RespPRRS/Repro vaccine strain, the $\mathrm{CH}-1 \mathrm{R}$ vaccine strain (attenuated vaccine strain derived from $\mathrm{CH}-\mathrm{la}$ ), and the attenuated live vaccine strain derived from JXA1. 


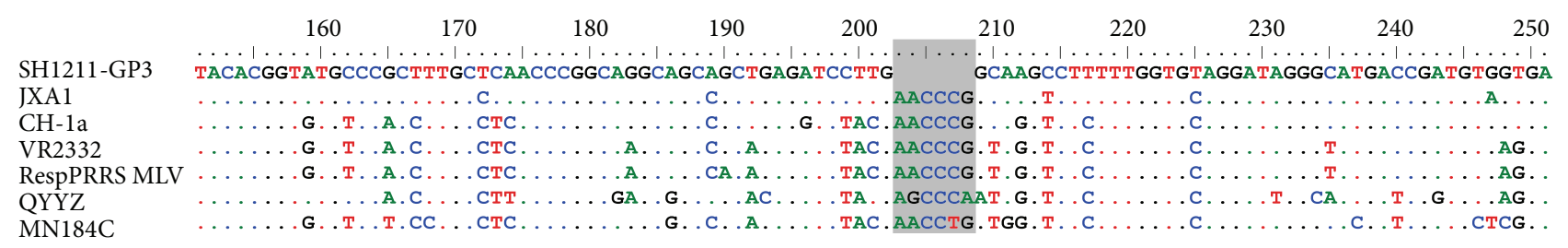

(a)

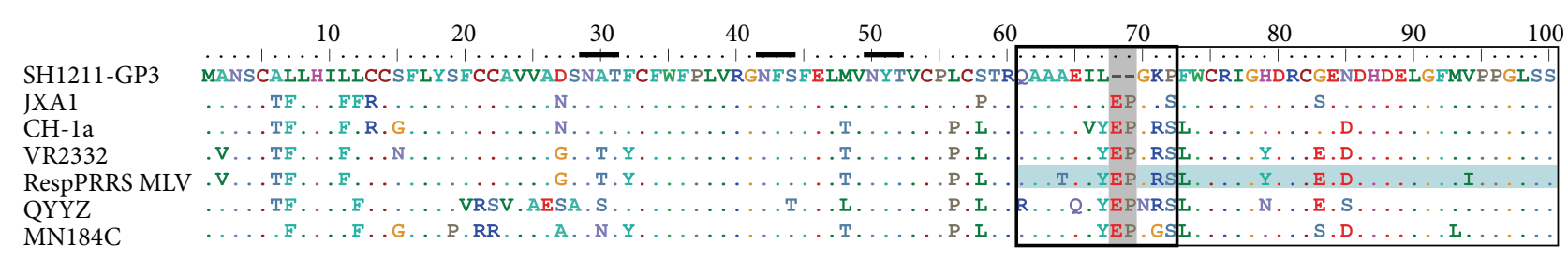

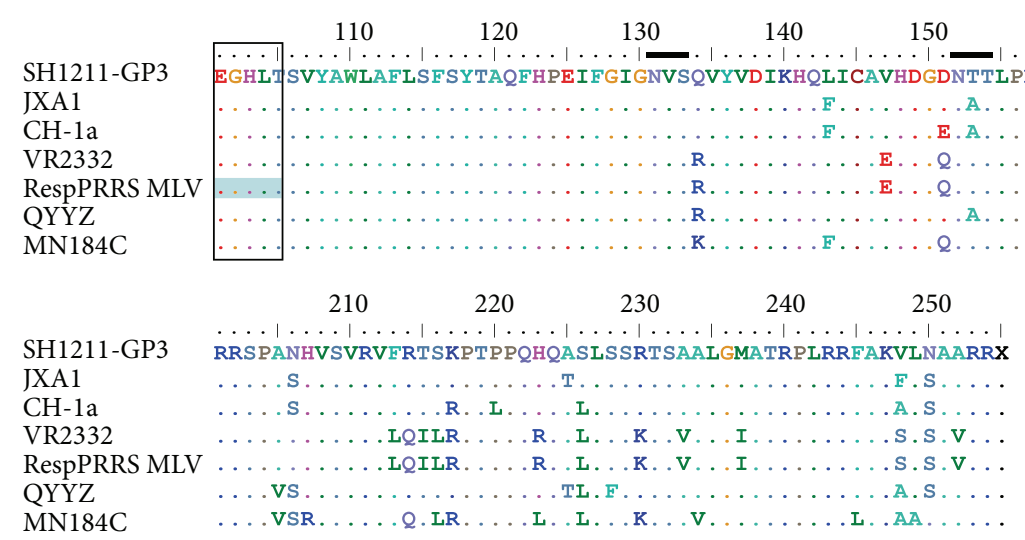

(b)

FIGURE 5: Alignment of partial GP3 nucleotide sequence (a) and whole GP3 amino acid sequences (b) of SH1211 with several representative PRRSV strains. The nucleotide and amino acid deletions are shown with grey bar; the key amino acid mutations are shown with blue bar. The antigenic region $\mathrm{Q}^{61} \mathrm{AARQRLEPGRN}{ }^{72}$ and the immunoreactive area (AA positions 61-105) are indicated by black boxes. The short lines represent N-glycosylation sites.

The decoy epitope of GP5 is comprised of $(\mathrm{A} / \mathrm{V})^{27} \mathrm{LVN}$ near the PNE, and may delay the production of virusneutralizing antibodies [32]. However, no AA mutations were found in the decoy epitope of the GP5 of the SH1211 strain. A recent study identified two identical signal peptide cleavage sites in the GP5 of PRRSVs, which results in a mixture of GP5 proteins in virus particles, one with and one without the decoy epitope [42]. By comparing the cleavage of wild-type GP5 to that of mutant viruses in which cleavage site 1 or 2 was blocked, the majority of GP5 was found to be cleaved at site 2, which deleted the decoy epitope. Thus, other factors may play vital roles in delaying the production of virus-neutralizing antibodies [42]. Residues 13 and 151 of GP5 are associated with the virulence of PRRSVs. The $R^{13} \rightarrow Q^{13}$ and $R^{151} \rightarrow G^{151} A A$ substitutions in VR-2332 resulted in the attenuation of the RespPRRS MLV vaccine strain [6]. The GP5 of the SH1211 strain contained $\mathrm{H}^{13}$ and $\mathrm{K}^{151}$ at these key residues. Future studies of the virulence of the SH1211 strain are warranted to determine the influence of these mutations in GP5 on pathogenicity.

The number of the potential N-glycosylation sites apparently increased in the Chinese isolates over time [43]. Additional $\mathrm{N}$-glycosylation sites may lead to an increase in the number of the $\mathrm{N}$-linked glycans on the envelope surface, which provide a barrier to antibodies. Variation in the glycan shield, therefore, presents a possible mechanism for reduced antigenicity [44]. In our current study, the GP5 of the SH1211 strain had N-glycosylation sites at positions 34,44 , and 51 only, which are identical to those in the classical PRRSV strain, $\mathrm{CH}-1 \mathrm{a}$. However, the high morbidity and mortality in the SH1211-infected herd indicate that other important factors contribute to the virulence of the virus. A recent study showed that an ORF5a wobble position in PRRSVs is used as a highly selective codon usage mechanism that conserves the RQ-motif in the ORF5a protein, despite significant selective pressure on the GP5 N-linked glycosylation motifs [45]. Future studies of the relationship between the variations in ORF5a protein and the N-glycosylation sites in GP5 of the SH1211 strain are warranted.

The ORF2 and ORF5 of the SH1211 strain shared high levels of sequence identity with the QYYZ strain. However, the remaining ORFs of SH1211 shared higher levels of sequence identity with the JXA1 strain. In the phylogenetic trees based on the ORF2 and ORF5 nucleotide sequences, the SH1211 strain clustered with the QYYZ strain, whereas the phylogenetic tree based on the complete genome sequence 


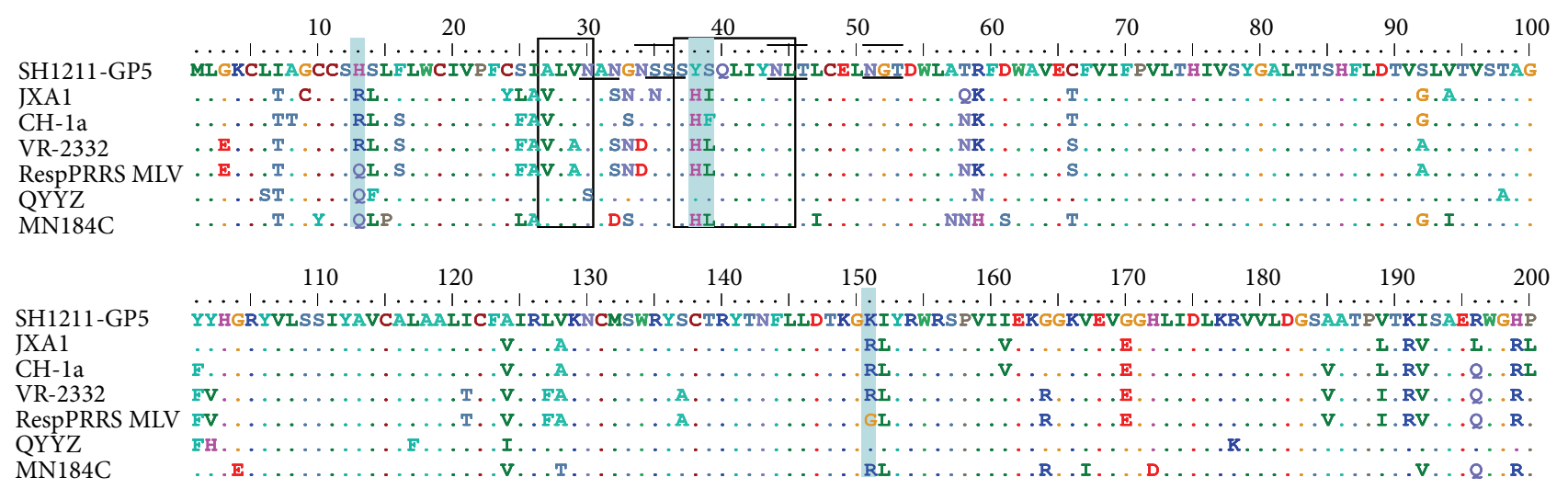

FIGURE 6: Alignment of whole GP5 amino acid sequence of SH1211 with several representative PRRSV strains. The key amino acid mutations within the different strains are shown with blue bar. The decoy epitope and the primary neutralizing epitope (PNE) are indicated by boxes. The short lines represent N-glycosylation sites.

showed substantially different relationships between the SH1211 strain and other PRRSVs. Therefore, we analyzed possible recombination events in the SH1211 strain, and the results indicated that the nucleotide sequences from positions 11 697-12 768 and 13 819-14 472 of SH1211 were derived from the QYYZ strain, while the remaining segments were from the HP-PRRSV strain, JXA1. The two recombinant QYYZlike regions contained the ORFs encoding the GP2 and GP5 proteins. Thus, these recombination events might have contributed to the virulence of the SH1211 strain. Because the sequence identities shared between the SH1211 and QYYZ strains for the two recombinant regions were $92.9 \%$ and $92.8 \%$, the statistical significance of the recombination breakpoints indicates that the SH1211 strain is a recombinant virus derived from the HP-PRRSV strain, JXA1, and the wildtype PRRSV strain, QYYZ.

The ORFla and ORF1b of PRRSVs encode the long nonstructural polyproteins, PPla and PPlab, with the expression of the latter depending on a ribosomal frame-shift signal in the ORF1a/ORF1b overlap region [46]. The PP1a and PPlab polyproteins are cleaved by viral proteases to release 14 nonstructural proteins, which include four proteases (Nspl $\alpha$, Nsp1 $\beta$, Nsp2, and Nsp4), an RNA-dependent RNA polymerase (Nsp9), a helicase (Nsp10), and an endonuclease (Nsp11) [46-48]. The Nsp1 $\beta$ protein functions in the inhibition of interferon (IFN)- $\beta$ transcription [49], suppresses both IRF3- and NF- $\kappa$ B-mediated IFN gene expression [49-51], and interferes with IFN-induced JAK-STAT signaling [50, 52]. A recent study indicated that the $\mathrm{Nspl} \beta$ blocks the nuclear translocation of interferon-stimulated gene factor 3 (ISGF3) by inducing the degradation of karyopherin- $\alpha 1$ and that $\mathrm{V}^{19}$ in the Nspl $\beta$ protein correlates with the inhibition of ISGF3 translocation [53].

Among the nonstructural proteins of the SH1211 strain of PRRSV, the Nsp $1 \beta$ shared the lowest level of sequence identity (92.6\%) with JXA1. Whether the high frequency of mutations in the Nsp1 $\beta$ protein contributes to the suppression of the host innate immune response to the SH1211 strain remains unclear. In addition, the $5^{\prime}$ and $3^{\prime}$ UTRs of PRRSVs have been shown to be important regulatory elements $[54,55]$.
Future studies are warranted to determine whether the nucleotides deletions in the $5^{\prime}$ and $3^{\prime}$ UTRs affect the replication, transcription, and virulence of the SH1211 strain.

\section{Conclusions}

The SH1211 strain represents a recently emerging virus with a genome structure that is typical of PRRSVs with unique genetic variation, including a deletion in the GP3 gene and apparent recombinations involving the coding sequences for the GP2 and GP5 proteins. Our sequence analysis of the SH1211 strain provides insight into the role of genetic variation in the antigenicity of PRRSVs in China. Future studies of the immunogenicity and pathogenicity of the SH1211 strain are warranted to identify the mechanisms underlying the contribution of genetic variation in PRRSVs to host-pathogen interactions.

\section{Conflict of Interests}

The authors declare that there is no conflict of interests regarding the publication of this paper.

\section{Acknowledgments}

The study was supported by grants from the National Natural Science Foundation, China (Grant no. 31230071), the Ministry of Education, China (Grants nos. 313031 and 20120097110043), and the Ministry of Agriculture, China (Grant no. CARS-36), with additional funding provided by the Priority Academic Program for the Development of Higher Education Institutions in Jiangsu Province, China.

\section{References}

[1] E. J. Neumann, J. B. Kliebenstein, C. D. Johnson et al., "Assessment of the economic impact of porcine reproductive and respiratory syndrome on swine production in the United States," Journal of the American Veterinary Medical Association, vol. 227, no. 3, pp. 385-392, 2005. 
[2] Z. Pejsak, T. Stadejek, and I. Markowska-Daniel, “Clinical signs and economic losses caused by porcine reproductive and respiratory syndrome virus in a large breeding farm," Veterinary Microbiology, vol. 55, no. 1-4, pp. 317-322, 1997.

[3] G. Wensvoort, C. Terpstra, J. M. Pol et al., "Mystery swine disease in The Netherlands: the isolation of Lelystad virus," Veterinary Quarterly, vol. 13, no. 3, pp. 121-130, 1991.

[4] D. A. Benfield, E. Nelson, J. E. Collins et al., "Characterization of swine infertility and respiratory syndrome (SIRS) virus (isolate ATCC VR-2332)," Journal of Veterinary Diagnostic Investigation, vol. 4, no. 2, pp. 127-133, 1992.

[5] C. J. Nelsen, M. P. Murtaugh, and K. S. Faaberg, "Porcine reproductive and respiratory syndrome virus comparison: divergent evolution on two continents," Journal of Virology, vol. 73, no. 1, pp. 270-280, 1999.

[6] R. Allende, G. F. Kutish, W. Laegreid et al., "Mutations in the genome of porcine reproductive and respiratory syndrome virus responsible for the attenuation phenotype," Archives of Virology, vol. 145, no. 6, pp. 1149-1161, 2000.

[7] K.-K. Conzelmann, N. Visser, P. van Woensel, and H.-J. Thiel, "Molecular characterization of porcine reproductive and respiratory syndrome virus, a member of the arterivirus group," Virology, vol. 193, no. 1, pp. 329-339, 1993.

[8] J. J. M. Meulenberg, M. M. Hulst, E. J. de Meijer et al., "Lelystad virus, the causative agent of porcine epidemic abortion and respiratory syndrome (PEARS), is related to LDV and EAV," Virology, vol. 192, no. 1, pp. 62-72, 1993.

[9] W.-H. Wu, Y. Fang, R. Farwell et al., "A 10-kDa structural protein of porcine reproductive and respiratory syndrome virus encoded by ORF2b," Virology, vol. 287, no. 1, pp. 183-191, 2001.

[10] R. Allende, T. L. Lewis, Z. Lu et al., "North American and European porcine reproductive and respiratory syndrome viruses differ in non-structural protein coding regions," Journal of General Virology, vol. 80, no. 2, pp. 307-315, 1999.

[11] E. J. Snijder, H. van Tol, N. Roos, and K. W. Pedersen, "Non-structural proteins 2 and 3 interact to modify host cell membranes during the formation of the arterivirus replication complex," Journal of General Virology, vol. 82, no. 5, pp. 985994, 2001.

[12] E. A. Nelson, J. Christopher-Hennings, and D. A. Benfield, "Serum immune responses to the proteins of porcine reproductive and respiratory syndrome (PRRS) virus," Journal of Veterinary Diagnostic Investigation, vol. 6, no. 4, pp. 410-415, 1994.

[13] E. A. Nelson, J. Christopher-Hennings, T. Drew, G. Wensvoort, J. E. Collins, and D. A. Benfield, "Differentiation of U.S. and European isolates of porcine reproductive and respiratory syndrome virus by monoclonal antibodies," Journal of Clinical Microbiology, vol. 31, no. 12, pp. 3184-3189, 1993.

[14] T. Stadejek, A. Stankevicius, T. Storgaard et al., "Identification of radically different variants of porcine reproductive and respiratory syndrome virus in Eastern Europe: towards a common ancestor for European and American viruses," Journal of General Virology, vol. 83, no. 8, pp. 1861-1873, 2002.

[15] A. E. Firth, J. C. Zevenhoven-Dobbe, N. M. Wills et al., "Discovery of a small arterivirus gene that overlaps the gp5 coding sequence and is important for virus production," Journal of General Virology, vol. 92, no. 5, pp. 1097-1106, 2011.

[16] C. R. Johnson, T. F. Griggs, J. Gnanandarajah, and M. P. Murtaugh, "Novel structural protein in porcine reproductive and respiratory syndrome virus encoded by an alternative orf5 present in all arteriviruses," Journal of General Virology, vol. 92, no. 5, pp. 1107-1116, 2011.

[17] X. J. Meng, "Heterogeneity of porcine reproductive and respiratory syndrome virus: implications for current vaccine efficacy and future vaccine development," Veterinary Microbiology, vol. 74, no. 4, pp. 309-329, 2000.

[18] Y. Fang, D.-Y. Kim, S. Ropp et al., "Heterogeneity in Nsp2 of European-like porcine reproductive and respiratory syndrome viruses isolated in the United States," Virus Research, vol. 100, no. 2, pp. 229-235, 2004.

[19] Z. Q. Gao, X. Guo, and H. C. Yang, "Genomic characterization of two Chinese isolates of Porcine respiratory and reproductive syndrome virus," Archives of Virology, vol. 149, no. 7, pp. 13411351, 2004.

[20] J. Han, Y. Wang, and K. S. Faaberg, "Complete genome analysis of RFLP 184 isolates of porcine reproductive and respiratory syndrome virus," Virus Research, vol. 122, no. 1-2, pp. 175-182, 2006.

[21] S. Shen, J. Kwang, W. Liu, and D. X. Liu, "Determination of the complete nucleotide sequence of a vaccine strain of porcine reproductive and respiratory syndrome virus and identification of the Nsp2 gene with a unique insertion," Archives of Virology, vol. 145, no. 5, pp. 871-883, 2000.

[22] I. H. Ansari, B. Kwon, F. A. Osorio, and A. K. Pattnaik, "Influence of N-linked glycosylation of porcine reproductive and respiratory syndrome virus GP5 on virus infectivity, antigenicity, and ability to induce neutralizing antibodies," Journal of Virology, vol. 80, no. 8, pp. 3994-4004, 2006.

[23] P. Gonin, B. Pirzadeh, C. A. Gagnon, and S. Dea, "Seroneutralization of porcine reproductive and respiratory syndrome virus correlates with antibody response to the GP5 major envelope glycoprotein," Journal of Veterinary Diagnostic Investigation, vol. 11, no. 1, pp. 20-26, 1999.

[24] H. Mardassi, S. Mounir, and S. Dea, "Molecular analysis of the ORFs 3 to 7 of porcine reproductive and respiratory syndrome virus, Quebec reference strain," Archives of Virology, vol. 140, no. 8, pp. 1405-1418, 1995.

[25] X.-J. Meng, P. S. Paul, P. G. Halbur, and I. Morozov, "Sequence comparison of open reading frames 2 to 5 of low and high virulence United States isolates of porcine reproductive and respiratory syndrome virus," Journal of General Virology, vol. 76, no. 12, pp. 3181-3188, 1995.

[26] H. Mardassi, S. Mounir, and S. Dea, "Structural gene analysis of a Quebec reference strain of porcine reproductive and respiratory syndrome virus (PRRSV)," Advances in Experimental Medicine and Biology, vol. 380, pp. 277-281, 1995.

[27] V. G. Andreyev, R. D. Wesley, W. L. Mengeling, A. C. Vorwald, and K. M. Lager, "Genetic variation and phylogenetic relationships of 22 porcine reproductive and respiratory syndrome virus (PRRSV) field strains based on sequence analysis of open reading frame 5," Archives of Virology, vol. 142, no. 5, pp. 9931001, 1997.

[28] V. Kapur, M. R. Elam, T. M. Pawlovich, and M. P. Murtaugh, "Genetic variation in porcine reproductive and respiratory syndrome virus isolates in the midwestern United States," Journal of General Virology, vol. 77, no. 6, pp. 1271-1276, 1996.

[29] D. Martin and E. Rybicki, "RDP: detection of recombination amongst aligned sequences," Bioinformatics, vol. 16, no. 6, pp. 562-563, 2000.

[30] M. Padidam, S. Sawyer, and C. M. Fauquet, "Possible emergence of new geminiviruses by frequent recombination," Virology, vol. 265, no. 2, pp. 218-225, 1999. 
[31] P. B. Das, H. L. X. Vu, P. X. Dinh et al., "Glycosylation of minor envelope glycoproteins of porcine reproductive and respiratory syndrome virus in infectious virus recovery, receptor interaction, and immune response," Virology, vol. 410, no. 2, pp. 385394, 2011.

[32] M. Ostrowski, J. A. Galeota, A. M. Jar, K. B. Platt, F. A. Osorio, and O. J. Lopez, "Identification of neutralizing and nonneutralizing epitopes in the porcine reproductive and respiratory syndrome virus GP5 ectodomain," Journal of Virology, vol. 76, no. 9, pp. 4241-4250, 2002.

[33] M. de Lima, I. H. Ansari, P. B. Das et al., "GP3 is a structural component of the PRRSV type II (US) virion," Virology, vol. 390, no. 1, pp. 31-36, 2009.

[34] W. Jiang, P. Jiang, Y. Li, X. Wang, and Y. Du, "Analysis of immunogenicity of minor envelope protein GP3 of porcine reproductive and respiratory syndrome virus in mice," Virus Genes, vol. 35, no. 3, pp. 695-704, 2007.

[35] M. P. Murtaugh, M. R. Elam, and L. T. Kakach, "Comparison of the structural protein coding sequences of the VR-2332 and Lelystad virus strains of the PRRS virus," Archives of Virology, vol. 140, no. 8, pp. 1451-1460, 1995.

[36] M. de Lima, A. K. Pattnaik, E. F. Flores, and F. A. Osorio, "Serologic marker candidates identified among B-cell linear epitopes of Nsp2 and structural proteins of a North American strain of porcine reproductive and respiratory syndrome virus," Virology, vol. 353, no. 2, pp. 410-421, 2006.

[37] M. Vanhee, W. van Breedam, S. Costers, M. Geldhof, Y. Noppe, and H. Nauwynck, "Characterization of antigenic regions in the porcine reproductive and respiratory syndrome virus by the use of peptide-specific serum antibodies," Vaccine, vol. 29, no. 2930, pp. 4794-4804, 2011.

[38] H. L. X. Vu, B. Kwon, K.-J. Yoon, W. W. Laegreid, A. K. Pattnaik, and F. A. Osorio, "Immune evasion of porcine reproductive and respiratory syndrome virus through glycan shielding involves both glycoprotein 5 as well as glycoprotein 3," Journal of Virology, vol. 85, no. 11, pp. 5555-5564, 2011.

[39] T.-Q. An, Y.-J. Zhou, G.-Q. Liu et al., "Genetic diversity and phylogenetic analysis of glycoprotein 5 of PRRSV isolates in mainland China from 1996 to 2006: coexistence of two NAsubgenotypes with great diversity," Veterinary Microbiology, vol. 123, no. 1-3, pp. 43-52, 2007.

[40] S. A. Dee, M. Torremorell, K. Rossow, C. Mahlum, S. Otake, and K. Faaberg, "Identification of genetically diverse sequences (ORF 5) of porcine reproductive and respiratory syndrome virus in a swine herd," Canadian Journal of Veterinary Research, vol. 65, no. 4, pp. 254-260, 2001.

[41] P. G. W. Plagemann, "The primary GP5 neutralization epitope of North American isolates of porcine reproductive and respiratory syndrome virus," Veterinary Immunology and Immunopathology, vol. 102, no. 3, pp. 263-275, 2004.

[42] B. Thaa, B. C. Sinhadri, C. Tielesch, E. Krause, and M. Veit, "Signal peptide cleavage from GP5 of PRRSV: a minor fraction of molecules retains the decoy epitope, a presumed molecular cause for viral persistence," PLoS One, vol. 8, no. 6, Article ID e65548, 2013.

[43] B. Li, L. Fang, X. Guo et al., "Epidemiology and evolutionary characteristics of the porcine reproductive and respiratory syndrome virus in China between 2006 and 2010," Journal of Clinical Microbiology, vol. 49, no. 9, pp. 3175-3183, 2011.

[44] D. J. Vigerust and V. L. Shepherd, "Virus glycosylation: role in virulence and immune interactions," Trends in Microbiology, vol. 15, no. 5, pp. 211-218, 2007.
[45] S. R. Robinson, J. E. Abrahante, C. R. Johnson, and M. P. Murtaugh, "Purifying selection in porcine reproductive and respiratory syndrome virus ORF5a protein influences variation in envelope glycoprotein 5 glycosylation," Infection, Genetics and Evolution C, vol. 20, pp. 362-368, 2013.

[46] E. J. Snijder and J. J. M. Meulenberg, "The molecular biology of arteriviruses," Journal of General Virology, vol. 79, no. 5, pp. 961-979, 1998.

[47] J. A. Den Boon, K. S. Faaberg, J. J. M. Meulenberg et al., "Processing and evolution of the N-terminal region of the arterivirus replicase ORFla protein: identification of two papainlike cysteine proteases," Journal of Virology, vol. 69, no. 7, pp. 4500-4505, 1995.

[48] J. Ziebuhr, E. J. Snijder, and A. E. Gorbalenya, "Virus-encoded proteinases and proteolytic processing in the Nidovirales," Journal of General Virology, vol. 81, no. 4, pp. 853-879, 2000.

[49] L. K. Beura, S. N. Sarkar, B. Kwon et al., "Porcine reproductive and respiratory syndrome virus nonstructural protein $1 \beta$ modulates host innate immune response by antagonizing IRF3 activation," Journal of Virology, vol. 84, no. 3, pp. 1574-1584, 2010.

[50] Z. Chen, S. Lawson, Z. Sun et al., "Identification of two autocleavage products of nonstructural protein 1 (nsp1) in porcine reproductive and respiratory syndrome virus infected cells: nspl function as interferon antagonist," Virology, vol. 398, no. 1, pp. 87-97, 2010.

[51] C. Song, P. Krell, and D. Yoo, "Nonstructural protein $1 \alpha$ subunit-based inhibition of NF- $\kappa \mathrm{B}$ activation and suppression of interferon- $\beta$ production by porcine reproductive and respiratory syndrome virus," Virology, vol. 407, no. 2, pp. 268-280, 2010.

[52] D. Patel, Y. Nan, M. Shen, K. Ritthipichai, X. Zhu, and Y.-J. Zhang, "Porcine reproductive and respiratory syndrome virus inhibits type I interferon signaling by blocking STAT1/STAT2 nuclear translocation," Journal of Virology, vol. 84, no. 21, pp. 11045-11055, 2010.

[53] R. Wang, Y. Nan, Y. Yu, and Y. -J. Zhang, "Porcine reproductive and respiratory syndrome virus Nsplbeta inhibits interferon-activated JAK/STAT signal transduction by inducing karyopherin-alphal degradation," Journal of Virology, vol. 87, no. 9, pp. 5219-5228, 2013.

[54] C. Tan, L. Chang, S. Shen, D. X. Liu, and J. Kwang, "Comparison of the 5/ leader sequences of North American isolates of reference and field strains of porcine reproductive and respiratory syndrome virus (PRRSV)," Virus Genes, vol. 22, no. 2, pp. 209217, 2001.

[55] M. H. Verheije, R. C. L. Olsthoorn, M. V. Kroese, P. J. M. Rottier, and J. J. M. Meulenberg, "Kissing interaction between $3 /$ noncoding and coding sequences is essential for Porcine arterivirus RNA replication," Journal of Virology, vol. 76, no. 3, pp. 1521-1526, 2002. 

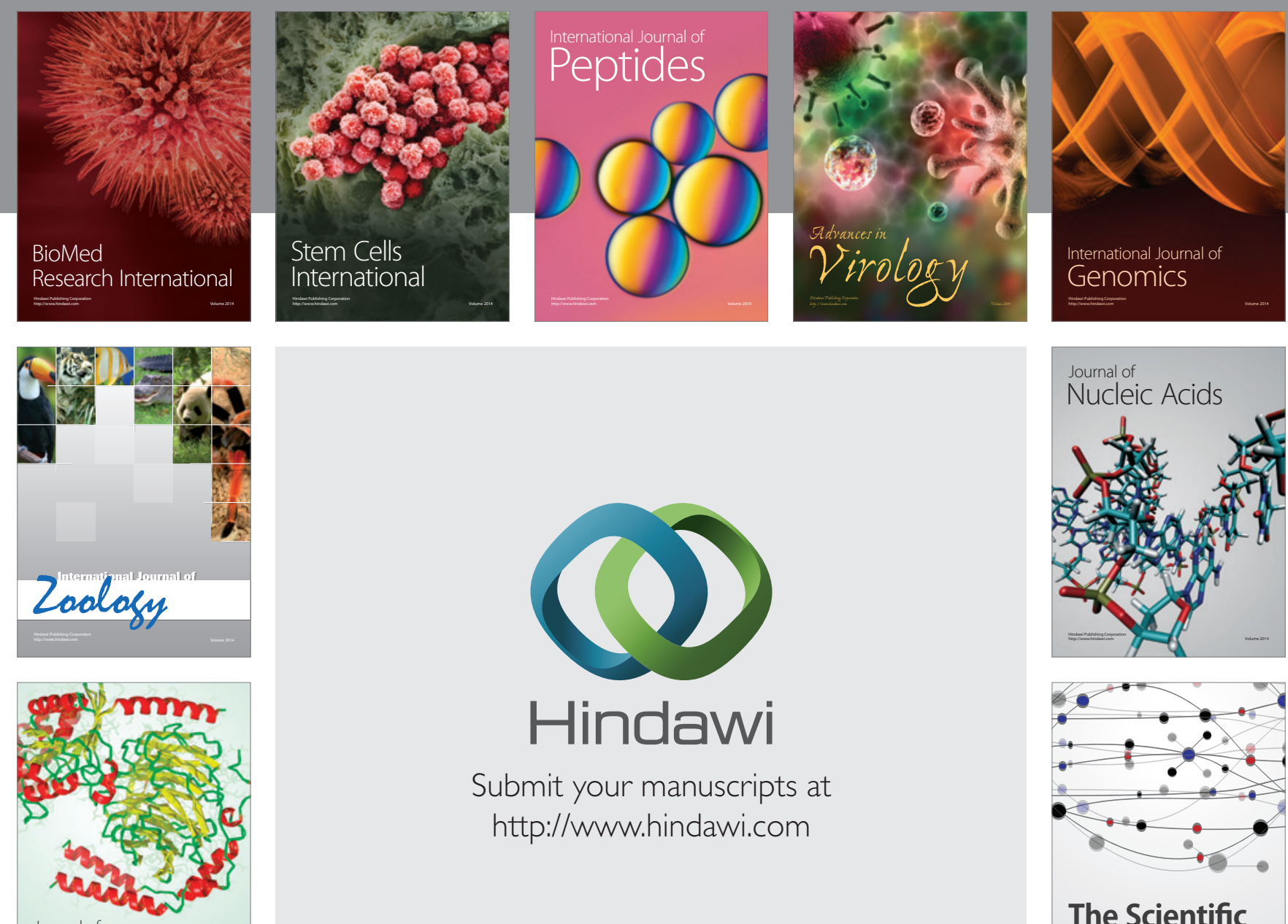

Submit your manuscripts at

http://www.hindawi.com

Journal of
Signal Transduction
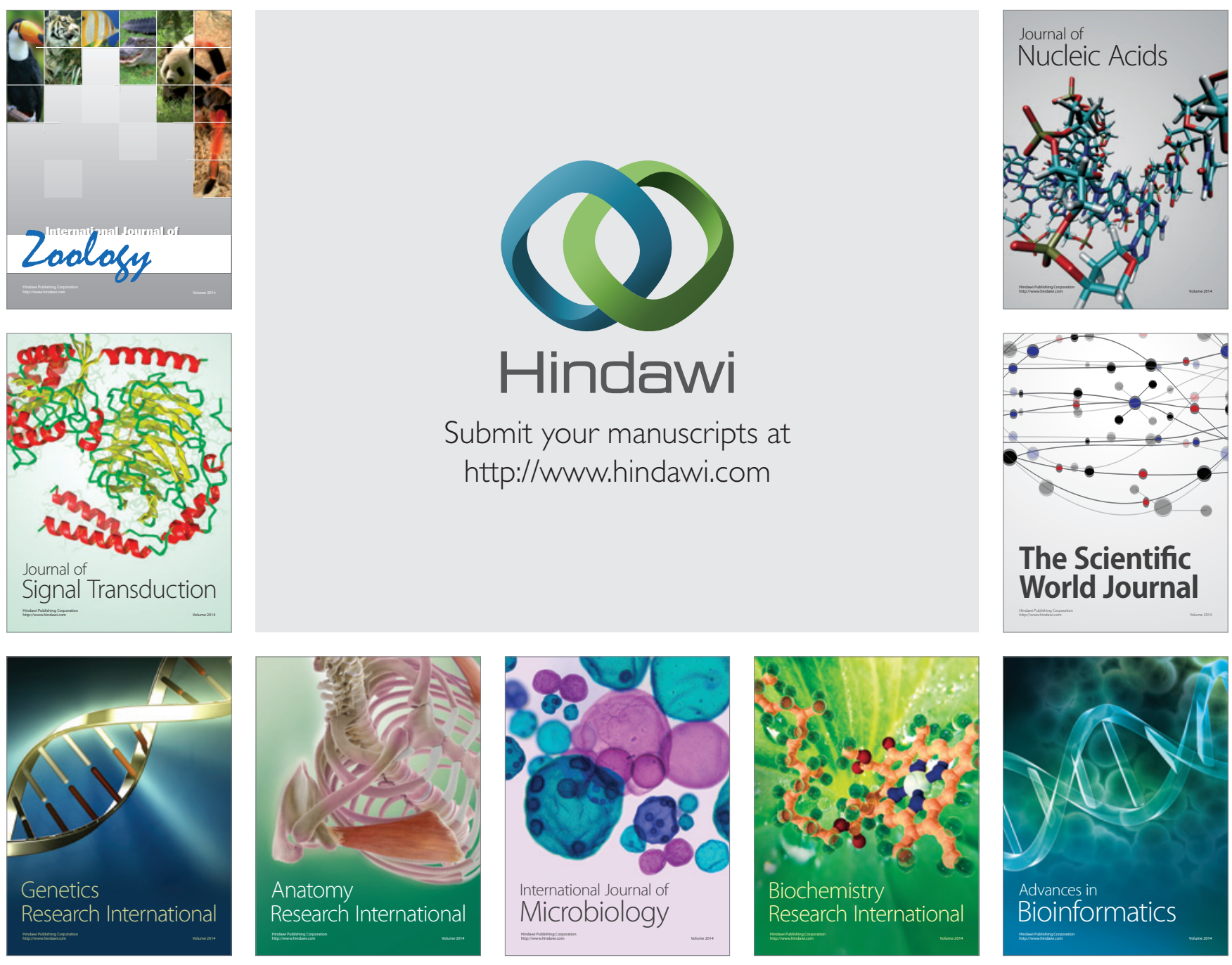

The Scientific World Journal
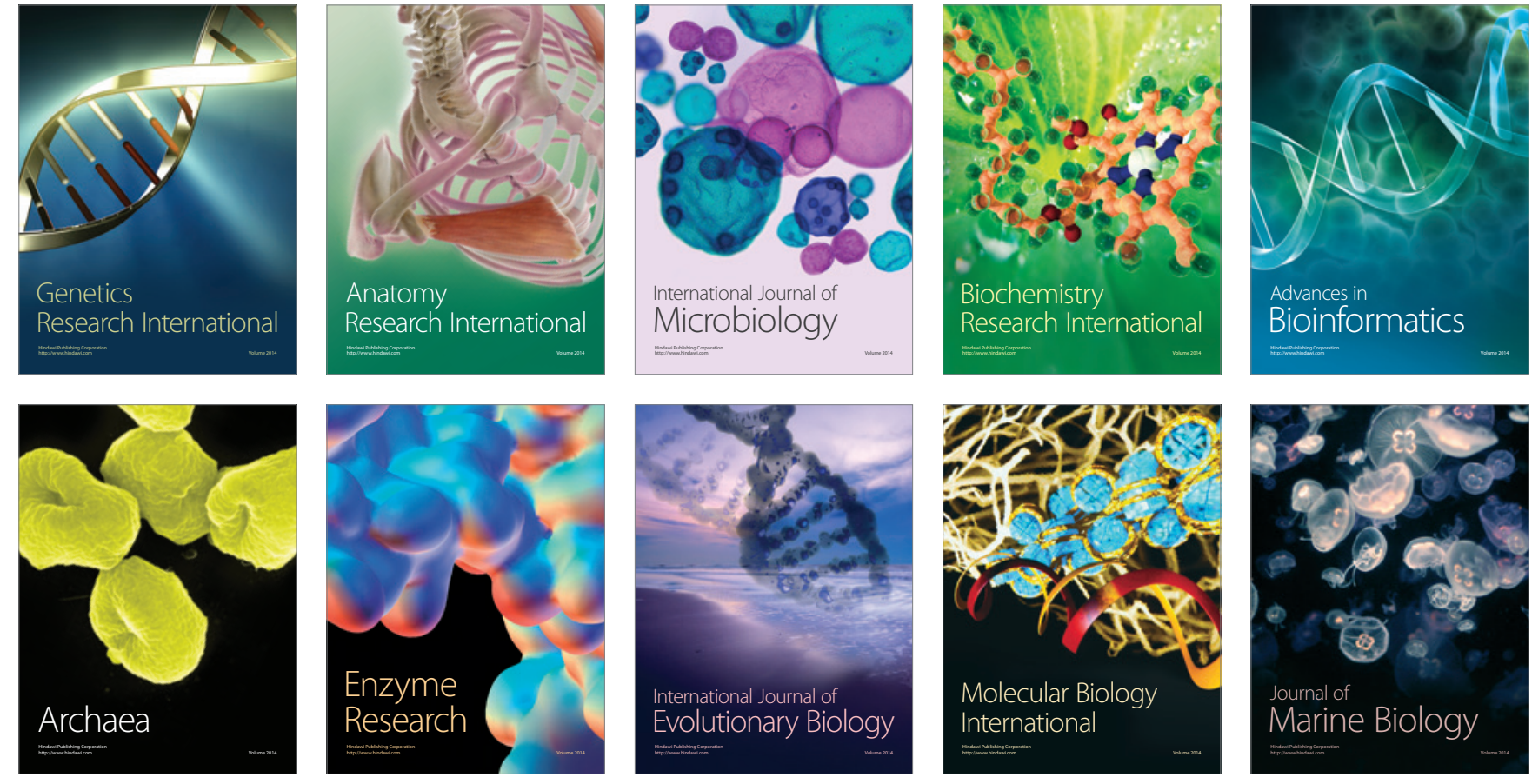